\title{
UCRL-TR-216589
}

LAW RENCE LIVERMORE N A T IO N A L LABORATORY
In-vivo imaging of the photoreceptor mosaic in retinal dystrophies and correlations with visual function

S. Choi, N. Doble, J. Hardy, S. Jones, J. Keltner, S. Olivier, J. S. Werner

October 27, 2005 
This document was prepared as an account of work sponsored by an agency of the United States Government. Neither the United States Government nor the University of California nor any of their employees, makes any warranty, express or implied, or assumes any legal liability or responsibility for the accuracy, completeness, or usefulness of any information, apparatus, product, or process disclosed, or represents that its use would not infringe privately owned rights. Reference herein to any specific commercial product, process, or service by trade name, trademark, manufacturer, or otherwise, does not necessarily constitute or imply its endorsement, recommendation, or favoring by the United States Government or the University of California. The views and opinions of authors expressed herein do not necessarily state or reflect those of the United States Government or the University of California, and shall not be used for advertising or product endorsement purposes.

This work was performed under the auspices of the U.S. Department of Energy by University of California, Lawrence Livermore National Laboratory under Contract W-7405-Eng-48. 


\section{In-vivo imaging of the photoreceptor mosaic in retinal dystrophies and correlations with visual function}

Stacey S. Choi ${ }^{1}$, Nathan Doble ${ }^{2}$, Joseph $\operatorname{Hardy}^{3}$, Steve Jones ${ }^{4}$, John Keltner ${ }^{1}$,

Scot Olivier ${ }^{4}$, John S. Werner ${ }^{1}$

${ }^{1}$ Department of Ophthalmology \& Vision Science, University of California Davis, Sacramento, CA 95817

${ }^{2}$ Iris AO Inc, 2680 Bancroft Way, Berkeley, CA 94704

${ }^{3}$ Neuroscience Solutions, 114 Sansome Street, San Francisco, CA 94104

${ }^{4}$ Lawrence Livermore National Laboratory, Livermore, CA, 94551

Short title: Photoreceptor mosaic in retinal dystrophies

Word count (excluding references and legends): 4,436

Number of Tables and Figures: 7 figures, 2 tables

Keywords: adaptive optics, photoreceptors, retinal dystrophy, contrast sensitivity, mfERG, visual fields, cone density 
PURPOSE. To relate in-vivo microscopic retinal changes to visual function assessed with clinical tests in patients with various forms of retinal dystrophies.

METHODS. The UC Davis Adaptive Optics (AO) Fundus Camera was used to acquire in-vivo retinal images at the cellular level. Visual function tests, consisting of visual field analysis, multifocal electroretinography (mfERG), contrast sensitivity and color vision measures, were performed on all subjects. Five patients with different forms of retinal dystrophies and three control subjects were recruited. Cone densities were quantified for all retinal images.

RESULTS. In all images of diseased retinas, there were extensive areas of dark space between groups of photoreceptors, where no cone photoreceptors were evident. These irregular features were not seen in healthy retinas, but were characteristic features in fundi with retinal dystrophies. There was a correlation between functional vision loss and the extent to which the irregularities occurred in retinal images. Cone densities were found to decrease with an associated decrease in retinal function.

CONCLUSIONS. AO fundus photography is a reliable technique for assessing and quantifying the changes in the photoreceptor layer as disease progresses. Furthermore, this technique can be useful in cases where visual function tests give borderline or ambiguous results, as it allows visualization of individual photoreceptors. 
Retinal dystrophies are debilitating and currently incurable diseases that cause severe visual impairment from a very young age. Patients with cone and cone-rod dystrophies typically exhibit visual acuity loss, visual field impairment, color vision deficiency, photophobia and sometimes nystagmus, ${ }^{1-7}$ whereas patients with retinitis pigmentosa (RP), rod or rod-cone dystrophies show night blindness, peripheral visual field depressions or scotomas and in some patients, residual central vision ${ }^{8}$.

Electroretinography (ERG) has been the most important objective tool in monitoring the progression of retinal dystrophies. To assess central retinal function, the multifocal electroretinogram (mfERG) has been used ${ }^{9-12}$. It has been demonstrated that small remaining responses in the macular region can be reliably measured with mfERG in patients with $\mathrm{RP}^{12-14}$.

Color vision tests have also been used in monitoring the progression of retinal dystrophies as cones are affected in most cases. Fishman et al. ${ }^{15}$ examined 67 patients with various types of RP for color vision defects. They used the Farnsworth-Munsell 100-hue test and found that when an atrophic macular lesion was present or if visual acuity was less than 20/30, none of the patients had normal color vision. RP patients with cystoid macular edema tested better than patients with foveal lesions. Heckenlively et al. ${ }^{16}$ evaluated color vision abnormalities in all forms of inherited cone-rod dystrophy. Of 40 eyes, 37 had abnormal error scores on the Farnsworth-Munsell 100-hue test, even though the average visual acuity was 20/30. Tritanomalous defects were the most common finding in these patients. More recently, in a large psychophysical study, similar results were found: the majority of patients with cone and cone-rod dystrophies exhibited marked color vision defects, and the magnitude of defects correlated with the loss of visual acuity ${ }^{17}$.

Foveal cone functions in patients with retinal dystrophy can be inferred from visual 
acuity and contrast sensitivity ${ }^{18-25}$. In comparison to visual acuity, however, contrast sensitivity is a more sensitive indicator of abnormal central visual function in diseased retinas ${ }^{18-22}$. Patients with better visual acuity (20/30 or better, e.g., with RP) showed substantially reduced contrast sensitivity especially at high spatial frequencies, whereas patients with poor visual acuity (e.g. with cone dystrophy) showed normal sensitivity to lower spatial frequency gratings.

Numerous histological studies have demonstrated both rod and cone photoreceptor degeneration with progression of retinal dystrophies ${ }^{26-31}$. Photoreceptors are either missing or have shortened and severely distorted outer segments. A common biochemical defect has been identified in early onset retinal dystrophies in three different species of animals: rats, mice and $\operatorname{dogs}^{32-34}$. In each of these animals, there was evidence of an abnormality in the cyclic nucleotide metabolism, leading to the death of photoreceptor cells. Mullen and Lavail ${ }^{35}$ demonstrated that a failure of the phagocytic relationship between the photoreceptor cells and the RPE leads to degenerative changes in the photoreceptors in chimeric rats. Chaitin and Hall ${ }^{36}$ were able to show more specifically that the defect is not in the initial part of the phagocytic mechanism (i.e., binding and recognition), but occurs in the middle stages of ingestion or engulfment in RCS rats.

Even though a great deal of information has been learned through histological studies, it can be limited by artifacts during preparation of the retina, which further complicates the interpretation of disease processes at different stages. With the availability of $\mathrm{AO}$, it is now possible to image individual photoreceptors in living human eyes ${ }^{37}$. Roorda reported the first AO images on a cone dystrophy patient and showed the retina was patchy due to photoreceptor dropout $^{38}$. An overview of high-resolution retinal imaging using AO is provided by Doble ${ }^{39}$.

Previous studies have concentrated on imaging diseased eyes but none has attempted to correlate disease-associated changes in these images (i.e., cone loss) with tests of visual function. 
The aim of this study was to quantify and correlate the changes observed in high-resolution AO retinal images with various visual function tests used in clinical settings to explore the utility of this imaging modality for diagnosis and monitoring of retinal dystrophies.

\section{METHODS}

\section{Subjects}

Five patients with different forms of retinal dystrophies of unknown family history and three control subjects were tested. The patients included three cases of rod-cone dystrophy, one with cone dystrophy and one with cone-rod dystrophy. The age of all subjects ranged from 13 to 44 years with either no or minimal refractive error (i.e., less than $-2 \mathrm{D}$ for both spherical and astigmatic correction). Table 1(a) and (b) summarize the characteristics of all 8 subjects. Refractive error was corrected with trial lenses prior to AO retinal imaging and psychophysical testing; the auto-refractor unit was used for the mfERG. All subjects had bilateral changes, therefore the one eye with greater variation of visual field defects was chosen for the study. The pupil was dilated with one drop of $1 \%$ tropicamide followed by one drop of $2.5 \%$ phenylephrine for the AO retinal imaging and the mfERG measurements. For AO retinal imaging, the subject's head movement was minimized by using a bite-bar with a dental impression. For the contrast sensitivity measurements, a combination of a forehead and chin rest was used. The tenets of the

Declaration of Helsinki were observed and written informed consent was obtained after all procedures were fully explained and prior to any experimental measurements.

\section{Procedure}

\section{Photoreceptor Imaging}

Figure 1 shows a schematic of flood illuminated AO fundus camera in operation at UC 
Davis. The system consists of two parts: (i) the AO control loop which measures and corrects the ocular aberrations (shown by the dark gray shading) and (ii) the imaging camera / projector which provides for imaging and vision testing respectively (light gray).

\section{a. The AO control loop}

Trial lenses are used to correct sphere and cylinder prior to the AO implementation. The subject was then instructed to fixate on a target consisting of a series of concentric circles calibrated to different retinal eccentricities in degrees from the fovea. The fixation target subtended a visual angle of $\pm 8^{0}$. A superluminescent laser diode (SLD) (Hamamatsu Photonics, Model L8414-04, Japan) operating at $835 \pm 20 \mathrm{~nm}$ is used to form a wavefront sensor (WFS) beacon on the retina. The corneal irradiance was $63.9 \mu \mathrm{W}$, incident through a $1 \mathrm{~mm}$ entrance pupil. This is a factor of 3 below the recommended ANSI standard ${ }^{40}$. The SLD is coupled into the eye via a high quality pellicle beamsplitter (National Photocolor, Rochester, NY) and is delivered slightly off the corneal pole to avoid the corneal reflex ${ }^{41}$. The pellicle is optically flat in both transmission and reflection, which allows for a reference laser to be coupled into the system from the opposite side for calibration and alignment purposes.

Upon reflection from the retina, the $7 \mathrm{~mm}$ diameter exit pupil is relayed to the deformable mirror (DM) via a 10x magnification telescope. The DM was manufactured by Litton "ITEK" (DM109, Lexington, MA) and has 109 actuators arranged in a hexagonal array below a continuous front-surface mirror. The DM has an approximate mirror stroke of $\pm 2 \mu \mathrm{m}$. This conjugate pupil plane is then relayed to the wavefront sensor (WFS) via reflection from a high quality hot mirror. The WFS is Shack-Hartmann based, comprising a lenslet array (Adaptive Optics Associates, Inc. Cambridge, MA) and a Dalsa CA-D7 CCD camera (Dalsa, Waterloo, Ontario, Canada) located in the back focal plane of the lenslet array. The lenslets have a $24 \mathrm{~mm}$ 
focal length with a $400 \mu \mathrm{m}$ pitch. The $7 \mathrm{~mm}$ exit pupil is magnified onto the WFS by a factor of 1.14 and is sampled by 20 lenslets across the pupil diameter. The DM is operated using direct slope control ${ }^{42}$. Individual DM actuators are pushed and the resulting Shack-Hartmann WFS spot deflections are recorded. The resulting matrix is then inverted and used to calculate the required voltages to be sent to the actuators, directly from the measured slope offsets. This method removes the need for any wavefront reconstruction in the AO control loop. The aberrated wavefront is sampled at $20 \mathrm{~Hz}$ providing an experimentally measured closed-loop bandwidth of $\sim 0.9 \mathrm{~Hz}$. A gain factor of $30 \%$ is used. Both the WFS and DM are controlled through a standard 2.66 GHz personal computer. Typical RMS correction for a $7 \mathrm{~mm}$ pupil is $\sim 0.09 \mu \mathrm{m}$. The before and after wavefront map and the resulting PSF are shown in Figure 2. There was a decrease in RMS by a factor of 3 with an associated 3-fold increase in Strehl ratio. For imaging purposes, a smaller pupil of diameter $6.5 \mathrm{~mm}$ is used to avoid the edge artifacts due to DM correction at the pupil margins.

\section{b. Imaging camera}

Once the eye's aberrations have been corrected, a shutter is opened and a retinal image acquired on the imaging camera; the imaging path is shown with the lighter gray shading. The imaging pulse follows the corrected path of the DM and is transmitted through the hot mirror and is re-imaged onto a cooled CCD camera (Princeton Instruments, VersArray XP). The imaging source is a $300 \mathrm{~W}$ xenon arc lamp regulated by a dc power supply (Oriel, Stratford, CT). The imaging wavelength is broadly tunable over the visible and near infrared spectrum by choice of an appropriate interference filter. The exposure duration was set to 10 msec with 0.6 and $0.25 \mu \mathrm{J}$ of light being delivered through $40 \mathrm{~nm}$ FWHM interference filters centered at 550 and $650 \mathrm{~nm}$

respectively. This is a factor of 40 below the recommended ICNIRP guidelines ${ }^{43}$. To correct for 
the ocular longitudinal chromatic aberration between the WFS beacon at $835 \mathrm{~nm}$ and the visible wavelengths used for imaging, the imaging camera is mounted onto an axial translation stage to provide the chromatic aberration correction.

Five to seven best images were selected and then registered together via an autocorrelation process to optimize the contrast and improve the signal-to-noise ratio of the image $^{44}$.

\section{c. Cone density measurement}

Photoreceptor density was determined using a Matlab program (The Mathworks, Inc., Natick, MA) that automatically counted the cones once the images were registered. The initial, registered images, $I_{\text {orig }}$. were first convolved with a Gaussian filter and then subtracted from the initial profile to give the new image intensity profile, $I$. The process is described by equation (1)

$$
I=I_{\text {orig }}-I_{\text {orig }} * e^{-\left(x^{2}+y^{2}\right) / 2 \sigma^{2}}
$$

where the exponential describes a Gaussian filter of width $\sigma$ (i.e., the standard deviation) and $x$,

$y$ denote the coordinates of a pixel ${ }^{45}$. For this work, a $\sigma$ value of 30 was chosen. Figure 3(a) and (b) show the initial and filtered images respectively. To aid visualization of the filtered images, the values of $I$ were linearly scaled to increase brightness.

By determining the intensity of the dimmest cone, a threshold intensity level could then be set. The intensity profile of the image was divided into smaller sections of 10 intensity levels to search for the pixels that are brighter than the threshold intensity in each section. When a 'hot' pixel lies within a locus defined by the smallest center-to-center cone spacing, the program 
ignores that pixel value. This step ensures that cones are only counted once. Figure 3(c) shows the example image with all the cones highlighted. It is then a straightforward step to calculate the cone density.

\section{Functional Testing}

\section{a. Visual field analysis}

Prior to AO retinal imaging, visual fields were measured in each eye using a Humphrey Visual Field analyzer (HFA II - I series, Carl Zeiss Meditec, Inc., Dublin, CA) with SITA standard settings to determine the areas of reduced retinal sensitivity within the central 20-50 degrees of visual field. This helped us to decide which eye to test, and to target the areas of different severity for the AO retinal imaging. Depending on the severity of visual field loss, either a 24-2 or a 10-2 full threshold test was used with size 3 stimulus (i.e., $3 \mathrm{~mm}$ circular stimulus on white background, $10 \mathrm{~cd} / \mathrm{m}^{2}$, with exposure duration of $\left.200 \mathrm{~ms}\right)$.

\section{b. Multifocal electroretinography}

The multifocal electroretinogram (mfERG) is routinely used to isolate retinal response at discrete locations and to detect retinal dysfunction that has not yet lead to visible changes in the fundus or global decreases in visual performance. This technique is based on a cross-correlation between hexagonal black-and-white stimulus changes and the local response of the retina, thus reflecting the first stage of retinal processing ${ }^{46}$. The protocol used was similar to the ISCEV Guidelines for multifocal ERG and was described in detail elsewhere ${ }^{47}$. Briefly, the recording was made under room light conditions with a dilated pupil $(\mathrm{d}>6 \mathrm{~mm})$. Correction of refractive error (between +6 and -6 D) was obtained using the refraction correction unit as part of the VERIS system (EDI, San Mateo, CA). The stimulus consisted of 103 hexagons that were not 
scaled with retinal eccentricity in order to facilitate comparison with the $1^{\circ}$ retinal areas used for AO retinal imaging and contrast sensitivity testing. A central cross (X) was used for fixation. The flash intensity was $2.67 \mathrm{~cd} . \mathrm{sec} . \mathrm{m}^{-2}\left(200 \mathrm{~cd} . \mathrm{m}^{-2}\right)$, the intensity of the dark areas was $<0.05$ cd.sec. $\mathrm{m}^{-2}\left(<4\right.$ cd. $\left.\mathrm{m}^{-2}\right)$ and the frame rate was $75 \mathrm{~Hz}$. Burian-Allen contact lens electrodes (Hansen Ophthalmic Development Laboratory, Iowa City, IA) were used as active electrodes. Standard m-sequence stimulation mode $(\mathrm{m}=14)$ was used resulting in a total recording time of $3.38 \mathrm{~min}$. The responses were then band-pass filtered between $10 \mathrm{~Hz}$ and $300 \mathrm{~Hz}$. Eight segments were used for each recording, and any segment contaminated by eye movements or artifacts was rejected and re-recorded. The pupil was continuously monitored with a camera.

\section{c. Contrast sensitivity function}

The contrast sensitivity function (CSF) was measured with a $33 \mathrm{~cm}$ CRT video monitor (Sony Multiscan G220) driven by a Macintosh G4 computer with an ATI Radeon 7500 video card (10-bit per gun). Gabor patches (sinusoidally modulated gratings windowed by a Gaussian envelope) were presented at the same size $\left(1^{\circ}\right)$ and retinal position as the $\mathrm{AO}$ images. Contrast thresholds were measured at 5 spatial frequencies (1, 2, 4, 8 and 14 cycles per degree) using software written in Matlab 5.2.1 and with the Psychophysics Toolbox extensions ${ }^{48,49}$. The monitor was characterized using a Minolta colorimeter (CS 100 Chroma Meter) and gamma corrected using the procedures set out in Brainard et al. ${ }^{50}$. Observer position was stabilized by a forehead and chin rest so that the screen was viewed monocularly at a distance of $80 \mathrm{~cm}$. All experiments were performed in a dark room. Before the CSF was measured, subjects were adapted to the luminance level of the background $\left(31.3 \mathrm{~cd} / \mathrm{m}^{2}\right)$ onto which the stimulus patch was presented for $10 \mathrm{~min}$, and then asked to maintain steady central fixation by looking at a fixation target throughout the experiment. At each retinal location, the contrast sensitivity 
threshold for all five spatial frequencies, presented in random order, was measured by using a QUEST adaptive tracking procedure ${ }^{51}$. The threshold value for each spatial frequency was taken as the geometric mean of the threshold estimates from two interleaved adaptive staircase tracks. Then the same procedure was repeated at the next retinal eccentricity. The subject's task was to judge in which of two temporal intervals, the grating was presented and to record the response by pressing the corresponding button on the response pad.

\section{d. Color vision tests}

Three color vision tests were used: Farnsworth D-15, Neitz Anomaloscope and the Cambridge Color Test (CCT). All the tests were performed monocularly with corrective lenses. The CCT (Cambridge Research Systems) is particularly useful in examining the changes in color discrimination that occur as a result of congenital or acquired conditions. With this test, Landolt-

C patterns ( 2 to $16 \mathrm{~cd} / \mathrm{m}^{2}$ ) were presented on a calibrated computer monitor using a video board with 15-bit per color channel resolution. Following 5 min dark adaptation, the subject's task was to detect the location of the gap in a Landolt C using a four-alternative forced choice, based on the principles of pseudo-isochromatic plates ${ }^{52}$. Stimuli were displayed for 5 seconds in each trial. Discrimination thresholds were defined by the minimum chromatic contrast required for detection of stimuli varied in terms of the stimulation of short-wave (tritan), middle-wave (deutan) and long-wave (protan) sensitive cones.

\section{RESULTS}

Figure 4 shows the AO images of a normal retina (control 1) at six retinal locations. The scale bar represents $10 \mu \mathrm{m}$ on the retina. The photoreceptor mosaic is regular across the retina without any missing cones in the healthy eye. The cones and the gaps between the cones increase in size with increasing eccentricity, as expected ${ }^{53}$. 
Figure 5(a)-(c) show the AO retinal images taken from subjects with rod-cone dystrophy (RCD 1, 2 and 3) at different retinal loci. The retinal locations were determined based on the visual field results so that the areas with varying severity of functional loss could be imaged by the AO fundus camera. The consistent finding in all rod-cone dystrophy subjects was that the cone mosaic is not regular in these eyes (unlike that of normal eyes) at the retinal locations where the sensitivity is reduced, (i.e., there were areas of dark spaces between groups of cones, where no cones were visible). Figure 5(d) and (e) show the AO images from cone-rod dystrophy and cone dystrophy patients respectively at different retinal eccentricities. These subjects also showed photoreceptor irregularity at the locations where retinal sensitivity was reduced.

Cone density was calculated for each retinal image, and there was a clear positive correlation with retinal sensitivity threshold (from all the functional tests). The greater the reduction of retinal sensitivity was, the greater the loss of cones in the images. Table 2 summarizes the cone density measurements from the AO retinal images for each location of retina for all subjects, and they are compared to the extrapolated values from Curcio's histology data $^{53}$. The relative percentage values provided an indication of relative cone loss at each retinal location. Across all subjects, regardless of the type of retinal dystrophy, there was a decrease in number with an increase in retinal sensitivity loss. Depending on the extent of retinal damage, the range over which the percentage value decreased was different between subjects. The variation of cone density from the least to the most affected areas was $96 \%-49 \%$ for RCD 1 , 59\%-32\% for RCD 2, 33\%-22\% for RCD 3 (3 rod-cone dystrophy cases), 41\%-26\% for CRD (cone-rod dystrophy) and $81 \%-9 \%$ for CD (cone dystrophy). These numbers provide a good quantitative index of cone loss in various forms of retinal dystrophy.

The mfERG was measured on all subjects. Figure 6(a)-(c) show the traces from rod-cone 
dystrophy subjects (RCD 1, 2, and 3). The first figure, (i), in each section shows the recordings from all 103 locations in the central 45 degrees of the retina. The overall pattern of cone responses in mfERG matched closely to the visual field result, i.e., the areas in the visual field that showed depression in retinal sensitivity, were registered with flatter traces and longer latencies. The second figure, (ii), shows the averaged cone responses from hexagons that correspond to the retinal locations used for AO imaging. The resolution of the mfERG is not fine enough to make a 1:1 correspondence with the AO imaging location. The size of each hexagon was calculated to be 4.4 degrees on the retina. Therefore in some cases, a single hexagon represents the combined responses from more than one imaging location, e.g., in RCD 1, trace \#1 represents averaged response from the area that includes both $2^{\circ}$ NVF and $2^{\circ}$ TVF and trace \#3 includes $7^{\circ}$ and $8^{\circ}$ TVFs. All three subjects showed that as retinal sensitivity decreased, the mfERG trace became gradually flatter with longer latencies between peaks. Figure 6(a)(ii)-(c)(ii) demonstrate this trend. The top trace represents averaged response from the retinal location that corresponds to healthier part(s) of the retina used for AO imaging. The bottom trace represents that of the most affected part of the retina imaged and the middle trace(s) represent intermediate locations. At the retinal locations that were significantly affected by the disease, the amplitudes of mfERG evoked responses were reduced almost to the extent that there were no visible responses. Figure 6(d) and (e) show the mfERG recordings from subjects with cone-rod dystrophy (subject CRD) and cone dystrophy (subject CD) respectively. Both subjects had no visible responses across all retinal locations (refer to Figure 6(d)(ii)-(e)(ii)). For CRD, trace \#1 represents averaged response from the area that includes $3^{\circ} \mathrm{NVF}$ and $4^{\circ} \mathrm{NVF}$, whereas trace \#2 represents averaged response that includes $1^{\circ}$ and $2^{\circ} \mathrm{NVFs}$.

The data displayed in the graphs in Figure 7(a)-(c) are the luminance contrast sensitivity 
function (CSF) measurements from the three rod-cone dystrophy subjects (RCD 1, 2 and 3) at each retinal location, and the results were compared to those of control subjects. Contrast sensitivity decreases were similar to the other functional tests and AO images, and diseaserelated reductions in log contrast sensitivity were roughly uniform across all spatial frequencies. Figure 7(d) and (e) show the results from the cone-rod dystrophy and cone dystrophy subjects respectively. The cone-rod dystrophy subject had significantly reduced CSFs at all retinal locations compared to the control subject, and also the CSF decreased with a decrease in retinal sensitivity (as measured from other functional tests in this study and AO images), refer to Figure 7(d). The cone dystrophy subject did not have measurable contrast sensitivity at any of the retinal locations tested, therefore showing flat CSFs, see Figure 7(e).

Color vision test showed that those subjects with good central vision (i.e., rod-cone dystrophy subjects) had normal color vision, whereas those with poor central vision (i.e., conerod dystrophy and cone dystrophy subjects) had generalized color vision defects, showing highly elevated threshold on all three cone axes of the Cambridge Colour Test.

\section{DISCUSSION}

The data presented here show a clear correlation between functional visual loss and the extent to which cone density decreases as measured from AO retinal images of retinal dystrophies. It is generally recognized that, regardless of differences in the underlying cause, the final common pathway of retinal degeneration is the apoptotic death of the photoreceptors ${ }^{26-31}$. Electron microscopic studies have revealed that cones of patients with retinal dystrophy have truncated outer segments that are composed of small groups of disoriented disk membranes and swollen inner segments. In the end, the course of the disease leads to death of both inner and outer segments leaving a residual photoreceptor cell of a spherical shape with little cytoplasm ${ }^{8}$. 
Such cell degeneration could explain the dark spaces seen in the AO retinal images. In healthy retinas, the photoreceptors reflect incident light from the junction of the inner and outer segments, and this light is wave-guided back through the pupil. Each bright spot in the AO image represents a dominant reflection from an individual photoreceptor.

When the cone density measurements from AO retinal images were compared with the mfERG recordings from corresponding areas, the analysis indicated that there is a clear correlation between the strength of mfERG responses and the cone density measurements, i.e., lower amplitudes and longer latencies of mfERG responses were associated with lower cone density measurements. Given the effectiveness of AO fundus photography for identifying diseased retina at a very early stage of disease progression, $\mathrm{AO}$ imaging has the clear potential of becoming an integral part of ophthalmic and optometric diagnostic regimens.

A reduction in cone density due to cone photoreceptor cell death seems a likely explanation for the predominant contrast sensitivity loss. In contrast to previous findings, where the contrast sensitivity was found to be mainly affected at higher spatial frequencies in diseased retinas ${ }^{18,22}$, the contrast sensitivity decreased across all spatial frequencies in all of our subjects with retinal dystrophies. The CSFs for the cone dystrophy subject were flat at all retinal locations indicating no residual functional vision at those locations.

This study confirms earlier histological data by showing apoptotic death of the photoreceptors in diseased retinas in-vivo. The ability to monitor retinal changes at a cellular level in-vivo opens the possibility of (1) visualizing cellular changes without introducing artifacts from retinal preparation (2) a more sensitive method for quantifying the retinal changes, and (3) much earlier detection of any changes, which makes it possible to intervene with appropriate treatments at much earlier stage of disease. 
This is a clear demonstration of the applicability of the AO fundus camera in diagnosing as well as possibly monitoring the health of the retina at the sensitivity level that could not have been achieved by conventional clinical instruments. It will be of greater use, especially in cases where visual function tests lead to ambiguous or borderline results, by allowing one to visualize the photoreceptor layer in-vivo.

\section{ACKNOWLEDGEMENTS}

We thank Susan Garcia and Adam White for assistance in testing and Bai Xue for programming, and also Christina Gerth for valuable comments and Lawrence Morse and Susanna Park for help in patient diagnosis.

This study was supported by NEI EY 014743 and NIA A604058. 


\section{REFERENCES}

1 Berson EL, Gouras P, Gunkel RD. Progressive cone-rod degeneration. Arch Ophthalmol. 1968;80:68-76.

2 Birch DG, Fish GE. Rod ERGs in retinitis pigmentosa and cone-rod degeneration. Invest Ophthalmol Vis Sci. 1987;28:140-150.

3 Fishman GA. Progressive human cone-rod dysfunction (dystrophy). Trans Sect Ophthalmol Am Acad Ophthalmol Otolaryngol. 1976;81:OP716-OP724.

4 Goodman G, Ripps H, Siegel IM. Cone dysfunction syndromes. Arch Ophthalmol. 1963;70:214-231.

5 Ripps H, Noble KG, Greenstein VC, Siegel IM, Carr RE. Progressive cone dystrophy. Ophthalmology. 1987;94:1401-1409.

6 Szlyk JP, Fishman GA, Alexander KR, Peachey NS, Derlacki DJ. Clinical subtypes of conerod dystrophy. Arch Ophthalmol. 1993;111:781-788.

7 Yagasaki K, Jacobson SG. Cone-rod dystrophy: phenotypic diversity by retinal function testing. Arch Ophthalmol. 1989;107:701-708.

8 Heckenlively JR. Retinitis Pigmentosa. Philadelphia, Pennsylvania: J.B. Lippincott Company;1988.

9 Sutter EE, Tran D. The field topography of ERG components in man - I. The photopic luminance response. Vision Res. 1992;32:433-446.

10 Bearse MA, Sutter EE. Imaging localized retinal dysfunction with the multifocal electroretinogram. J Opt Soc Am A Opt Image Sci Vis. 1996;13:634-640. 
11 Gränse L, Abrahamsson M, Ponjavic V, Andréasson S. Electrophysiological findings in two young patients with Bothnia dystrophy and a mutation in the RLBP1 gene. Ophthalmic Genet. 2001;22:97-105.

12 Vajaranant TS, Seiple W, Szlyk JP, Fishman GA. Detection using the multifocal electroretinogram of mosaic retinal dysfunction in carriers of X-linked retinitis pigmentosa. Ophthalmology. 2002;109:560-568.

13 Gränse L, Ponjavic V, Andréasson S. Full field ERG, multifocal ERG and multifocal VEP in patients with retinitis pigmentosa and residual central visual fields. Acta Ophthalmo. Scand. 2004;82:701-706.

14 Holopigian K, Seiple W, Greenstein VC, Hood DC, Carr RE. Local cone and rod system function in patients with retinitis pigmentosa. Inves. Ophthalmol Vis Sci. 2001;42:779-788.

15 Fishman GA, Young RS, Vasquez V, Lourenco P. Color vision defects in retinitis pigmentosa. Ann Ophthalmol. 1981;13:609-618.

16 Heckenlively JR, Martin DA, Rosales TO. Telangiectasia and optic atrophy in cone-rod degenerations. Arch Ophthalmol. 1981;99:1983-1991.

17 Sadowski B, Zrenner E. Cone and rod function in cone degenerations. Vision Res. 1997;37:2303-2314.

18 Grover S, Fishman GA, Alexander KR, Anderson RJ, Derlacki DJ. Visual acuity impairment in patients with retinitis pigmentosa. Ophthalmology. 1996;103:1593-1600.

19 Marmor MF. Contrast sensitivity and retinal disease. Ann Ophthalmol. 1981;13:1069-1071.

20 Hyvärinen L, Rovamo J, Laurinen P, Peltomaa A. Contrast sensitivity function in evaluation of visual impairment due to retinitis pigmentosa. Acta Ophthalmol. 1981;59:763-773. 
21 Wolkstein M, Atkin A, Bodis-Wollner I. Contrast sensitivity in retinal disease. Ophthalmology. 1980;87:1140-1149.

22 Sucs FE, Uvijls A. Contrast sensitivity in retinitis pigmentosa at different luminance levels. Clin Vision Sci. 1992;7:147-151.

23 Lindberg CR, Fishman GA, Anderson RJ, Vasquez V. Contrast sensitivity in retinitis pigmentosa. Br J Ophthalmol. 1981;65:855-858.

24 Akeo K, Hiida Y, Saga M, Inoue R, Oguchi Y. Correlation between contrast sensitivity and visual acuity in retinitis pigmentosa patients. Ophthalmologica. 2002;216:185-191.

25 Alexander KR, Derlacki DJ, Fishman GA. Contrast thresholds for letter identification in retinitis pigmentosa. Invest Ophthalmol Vis Sci. 1992;33:1846-1852.

26 Bunt-Milam A, Kalian R, Pagan R. Clinical-ultra structural study of a retinal dystrophy. Invest Ophthalmol Vis Sci. 1983;24:458-469.

27 Flannery J, Farber D, Bird a, Book D. Degenerative changes in a retina affected with autonomic dominant retinitis pigmentosa. Invest Ophthalmol Vis Sci. 1989;30:191-211.

28 Szamier RB, Berson EL. Retinal ultrastructure in advanced retinitis pigmentosa. Invest Ophthalmol Vis Sci. 1977;16:947-962.

29 Szamier RB, Berson EL, Klein R, Meyers S. Sex-linked retinitis pigmentosa: ultrastructure of photoreceptors and pigment epithelium. Invest Ophthalmol Vis Sci 1979;18:145-160

30 Kolb H, Gouras P. Electron microscopic observations of human retinitis pigmentosa, dominantly inherited. Invest Ophthalmol Vis Sci. 1974;13:487-498.

$31 \mathrm{Li} \mathrm{Z}$, Jacobson S, Milam A. Autosomal dominant retinitis pigmentosa caused by the threonine-17 methionine rhodopsin mutation: retinal histopathology and immunocytochemistry. Exp Eye Res. 1994;58:397-408. 
32 Lolley RN, Farber DB, Rayborn ME, Hollyfield JG. Cyclic GMP accumulation causes degeneration of photoreceptor cells: simulation of an inherited disease. Science. 1977;196:664-666.

33 Farber DB, Lolley RN. Enzymatic basis for cyclic GMP accumulation in degenerative photoreceptor cells of mouse retina. J Cyclic Nucleotide Res. 1976;2:139-148.

34 Aguirre G, Farber D, Lolley R, Fletcher RT, Chader GJ. Rod-cone dysplasia in Irish setters: A defect in cyclic GMP metabolism in visual cells. Science. 1978;201:1133-1134.

35 Mullen RJ, Lavail MM. Inherited retinal dystrophy: Primary defect in pigment epithelium determined with experimental rat chimeras. Science. 1976;192:799-801.

36 Chaitin MH, Hall MO. Defective ingestion of rod outer segments by cultured dystrophic rat pigment epithelial cells. Invest Ophthalmol Vis Sci. 1983;24:812-820.

37 Liang J, Williams DR, Miller DT. Supernormal vision and high resolution retinal imaging through adaptive optics. J Opt Soc Am A. 1997; 14: 2884-2892.

38 Roorda A. Adaptive optics ophthalmoscopy. J Ref Surgery. 2000;16:S602-607.

39 Doble N. High resolution, in vivo retinal imaging using adaptive optics and its future role in ophthalmology. Expert Review of Medical Devices 2005;2:205-216.

40 American National Standard for the Safe Use of Lasers ANSI Z136.1. 1993 (Laser Institute of America, Orlando, FL).

41 Hofer H, Artal P, Singer B, Aragón JL, Williams DR. Dynamics of the eye's wave aberration. J Opt Soc Am A. 2001;18:497-506.

42 Jiang W, Li H. Hartmann-Shack wavefront sensing and control algorithm. Proceedings of SPIE. 1990;1271:82-93. 
43 Guidelines on Limits of exposure to broad-band Incoherent Optical Radiation (0.38 to $3 \mu \mathrm{m})$. Health Physics. 1997;73:539-554.

44 Brown LG. A survey of image registration techniques. ACM Computing Surveys. 1992;24:325-376.

45 Soliz P, Wilson M, Nemeth S, Nguyen P. Computer aided methods for quantitative assessment of longitudinal changes in retinal images presenting with maculopathy. Proceedings of SPIE. 2002;4681:159-170.

46 Sutter EE. The fast m-transform: a fast computation of cross-correlations with binary msequences. Soc Ind Appl Math. 1991;20:686-694.

47 Gerth C, Garcia SM, Ma L, Keltner JL, Werner JS. Multifocal electroretinogram: age-related changes for different luminance levels. Graefes Arch Clin Exp Ophthalmol. 2002;240:202208.

48 Brainard DH. The psychophysics toolbox. Spat Vis. 1997;10:433-436.

49 Pelli DG. The VideoToolbox software for visual psychophysics: transforming numbers into movies. Spat Vis. 1997;10:437-442.

50 Brainard DH, Pelli DG, Robson T. Encylopedia of Imaging Science and Technology. Display characterization. In H. J. (Ed.): Wiley; 2002:72-188.

51 Watson AB, Pelli DG. Quest: A bayesian adaptive psychometric method. Percept Psychophys. 1983;33:113-120.

52 Reffin JP, Astell S. Trials of a computer-controlled colour vision test that preserves the advantages of pseudoisochromatic plates. In Drum B, Moreland D, Serra A. eds. Colour Vision Deficiencies. London: Kluwer Academic Publishers; 1991:69-76. 
53 Curcio CA, Sloan KR, Kalina RE, Hendrickson AE, Human photoreceptor topography. $J$ Comp Neurol. 1990;292:497-523. 
Table 1. - Characteristics of (a) 5 subjects with various retinal dystrophies and (b) 3 control subjects.

(a)

\begin{tabular}{|c|c|c|c|c|c|c|}
\hline Subject & Gender & Age & Diagnosis & $\begin{array}{c}\text { Eye } \\
\text { Tested }\end{array}$ & $\begin{array}{c}\text { Visual } \\
\text { Acuity }\end{array}$ & $\begin{array}{c}\text { Visual } \\
\text { Field }\end{array}$ \\
\hline RCD 1 & Female & 33 & $\begin{array}{c}\text { Rod-cone } \\
\text { dystrophy }\end{array}$ & Left & $20 / 25$ & $\begin{array}{c}\text { Temporal } \\
\text { defect }\end{array}$ \\
\hline RCD 2 & Male & 31 & $\begin{array}{c}\text { Rod-cone } \\
\text { dystrophy }\end{array}$ & Left & $20 / 20$ & $\begin{array}{c}\text { Peripheral } \\
\text { ring defect }\end{array}$ \\
\hline RCD 3 & Male & 33 & $\begin{array}{c}\text { Rod-cone } \\
\text { dystrophy }\end{array}$ & Right & $20 / 20$ & $\begin{array}{c}\text { Temporal } \\
\text { arcuate } \\
\text { defect }\end{array}$ \\
\hline CRD & Male & 44 & $\begin{array}{c}\text { Cone-rod } \\
\text { dystrophy }\end{array}$ & Right & $20 / 80$ & $\begin{array}{c}\text { Central } \\
\text { scotoma }\end{array}$ \\
\hline CD & Female & 13 & $\begin{array}{c}\text { Cone } \\
\text { dystrophy }\end{array}$ & Left & $20 / 100$ & $\begin{array}{c}\text { Central } \\
\text { scotoma }\end{array}$ \\
\hline
\end{tabular}

(b)

\begin{tabular}{|c|c|c|c|c|}
\hline Subject & Gender & Age & Eye Tested & $\begin{array}{c}\text { Visual } \\
\text { Acuity }\end{array}$ \\
\hline Control 1 & Male & 20 & Left & $20 / 15$ \\
\hline Control 2 & Male & 33 & Left & $20 / 15$ \\
\hline Control 3 & Female & 41 & Right & $20 / 15$ \\
\hline
\end{tabular}


Table 2. - Cone density measurement from AO retinal images for all subjects. The order in which retinal locations are listed is going from the least to the most affected areas. NVF = nasal visual field, TVF $=$ Temporal Visual Field, TSVF $=$ Temporal Superior Visual Field, TIVF $=$ Temporal Inferior Visual Field, NSVF = Nasal Superior Visual Field, NIVF = Nasal inferior Visual Field.

\begin{tabular}{|c|c|c|c|c|c|}
\hline Subject & Diagnosis & $\begin{array}{c}\text { Retinal } \\
\text { location (VF } \\
\text { in degrees) }\end{array}$ & $\begin{array}{c}\text { Cone density } \\
\text { measurement } \\
(\text { cells/mm²) }\end{array}$ & $\begin{array}{l}\text { Extrapolation } \\
\text { from Curcio's } \\
\text { data (cells/mm²) }\end{array}$ & $\begin{array}{c}\text { Relative } \\
\%\end{array}$ \\
\hline \multirow{5}{*}{ RCD 1} & \multirow{5}{*}{$\begin{array}{l}\text { Rod-cone } \\
\text { dystrophy }\end{array}$} & $2^{\circ} \mathrm{NVF}$ & 41,450 & 43,000 & 96 \\
\hline & & $2^{\circ} \mathrm{TVF}$ & 29,625 & 40,000 & 74 \\
\hline & & $4^{\circ} \mathrm{TVF}$ & 15,075 & 25,000 & 61 \\
\hline & & $7^{\circ}$ TVF & 11,325 & 20,000 & 57 \\
\hline & & $8^{\circ}$ TVF & 7,825 & 16,000 & 49 \\
\hline \multirow{3}{*}{ RCD 2} & \multirow{3}{*}{$\begin{array}{l}\text { Rod-cone } \\
\text { dystrophy }\end{array}$} & $2^{\circ}$ TVF & 23,425 & 40,000 & 59 \\
\hline & & $4^{\circ} \mathrm{N} 4^{\circ}$ IVF & 10,525 & 20,000 & 53 \\
\hline & & $2^{\circ} \mathrm{N} 7^{\circ} \mathrm{SVF}$ & 5,625 & 18,000 & 32 \\
\hline \multirow{4}{*}{ RCD 3} & \multirow{4}{*}{$\begin{array}{l}\text { Rod-cone } \\
\text { dystrophy }\end{array}$} & $4^{\circ} \mathrm{T} 4^{\circ}$ IVF & 6,500 & 20,000 & 33 \\
\hline & & $5^{\circ} \mathrm{T} 3^{\circ} \mathrm{SVF}$ & 5,375 & 24,000 & 22 \\
\hline & & $5^{\circ} \mathrm{T} 7^{\circ} \mathrm{SVF}$ & 4,550 & 18,000 & 25 \\
\hline & & $7^{\circ} \mathrm{T} 7^{\circ} \mathrm{SVF}$ & 3,750 & 17,000 & 22 \\
\hline \multirow{4}{*}{ CRD } & \multirow{4}{*}{$\begin{array}{l}\text { Cone-rod } \\
\text { dystrophy }\end{array}$} & $4^{\circ} \mathrm{NVF}$ & 20,300 & 25,000 & 81 \\
\hline & & $3^{\circ} \mathrm{NVF}$ & 22,125 & 33,000 & 67 \\
\hline & & $2^{\circ} \mathrm{NVF}$ & 13,200 & 43,000 & 31 \\
\hline & & $1^{\circ} \mathrm{NVF}$ & 7,175 & 76,000 & 9 \\
\hline \multirow{3}{*}{$\mathrm{CD}$} & \multirow{3}{*}{$\begin{array}{c}\text { Cone } \\
\text { dystrophy }\end{array}$} & $4^{\circ} \mathrm{N} 4^{\circ} \mathrm{SVF}$ & 10,257 & 25,000 & 41 \\
\hline & & $4^{\circ} \mathrm{N} 4^{\circ}$ IVF & 7,075 & 20,000 & 35 \\
\hline & & $4^{\circ} \mathrm{T} 4^{\circ} \mathrm{IVF}$ & 5,125 & 20,000 & 26 \\
\hline
\end{tabular}




\section{FIGURE LEGENDS}

Figure 1 The Flood Illuminated Adaptive Optics Fundus Camera at UC Davis; the AO control loop is represented by dark gray shading while the imaging and vision testing paths are represented by light gray.

Figure 2 The Wavefront (WF) and PSF plots before and after AO correction. The measurements were taken over $7 \mathrm{~mm}$ pupil. The wavefront becomes flatter after AO correction. The RMS error decreases by a factor of 3. From the PSF plot, it can be observed that strehl ratio increases by a factor of 3 .

Figure 3 An example of the automated cone density measurement procedure. (a)

Cropped original image, (b) Image after background subtraction, (c) Outcome of cone density measurement: all the cones are accurately picked.

Figure 4 AO images of normal retina at six retinal locations on control subject 1 . The scale bar corresponds to $10 \mu \mathrm{m}$ on the retina. $\mathrm{N}=$ nasal, $\mathrm{S}=$ Superior, $\mathrm{I}=$ Inferior. $\mathrm{VF}=$ visual field.

Figure 5 AO corrected retinal images for each subject at different locations of the retina are shown with the corresponding visual field results. Retinal location is denoted in terms of visual field in degrees from the fovea. Separate panels denote different subjects, as indicated. Other details as in Fig. 4.

Figure 6 Multifocal ERG recordings showing the traces from all 103 hexagons as well as the ones that closely match with the retinal locations used for AO imaging. Changes in amplitude and latency were observed at different retinal eccentricities in each subject. 
Figure 7 Contrast sensitivity functions for retinal dystrophy patients and control subjects at the retinal locations corresponding to the locations imaged with AO. Separate graphs denote different subjects, as indicated. 


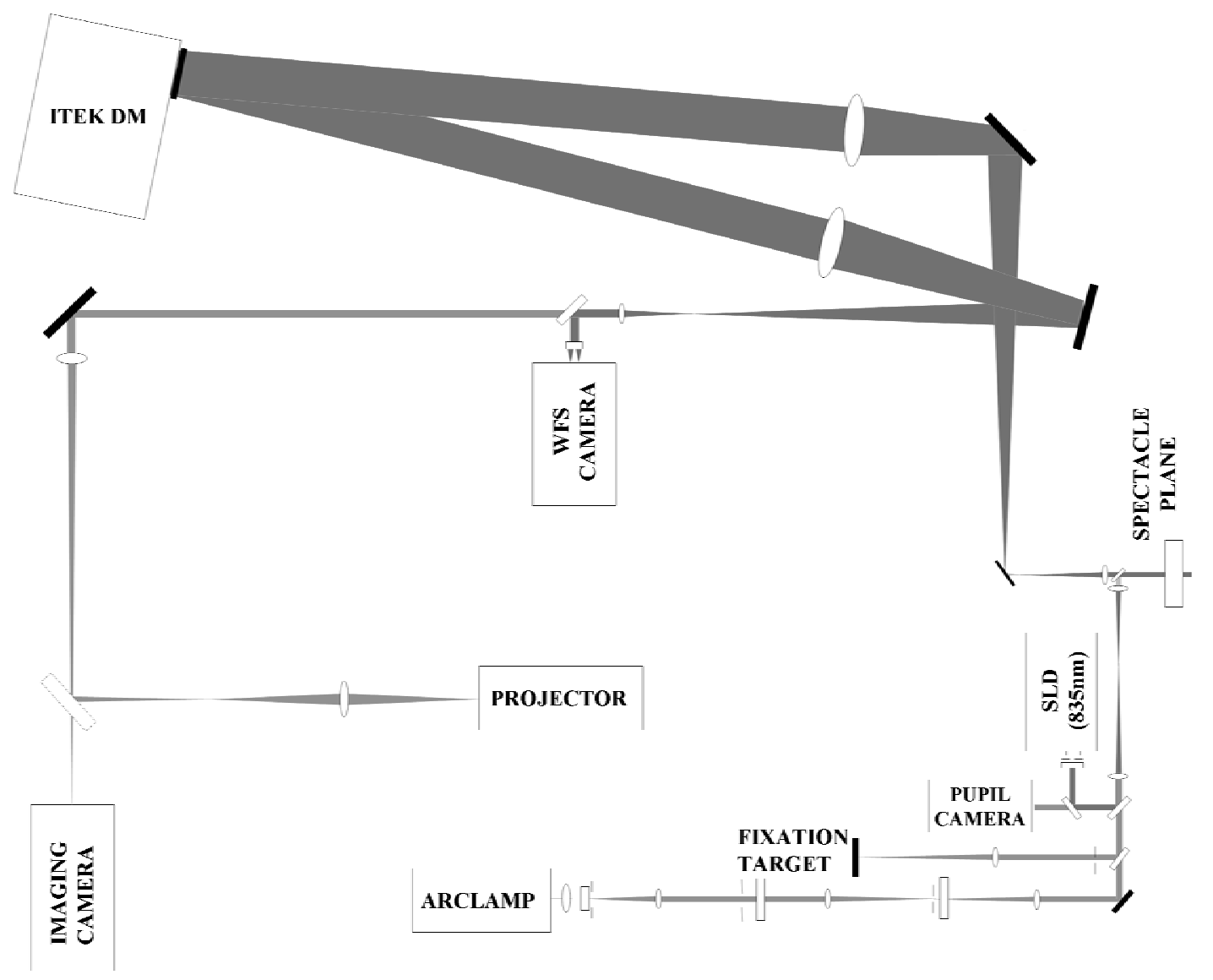

Figure 1. 


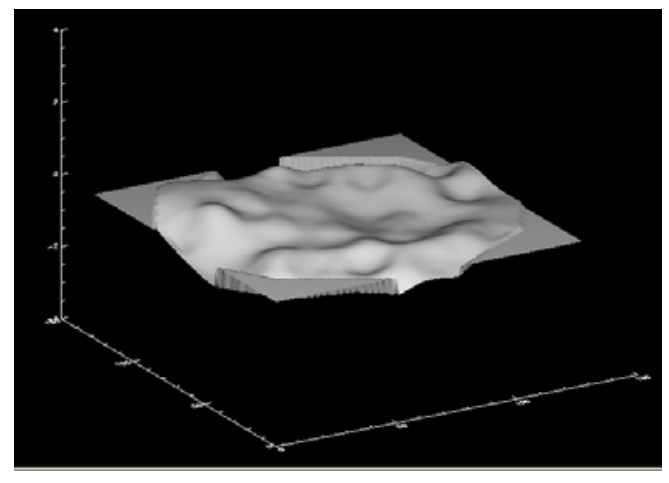

(a) WF Map without AO correction.

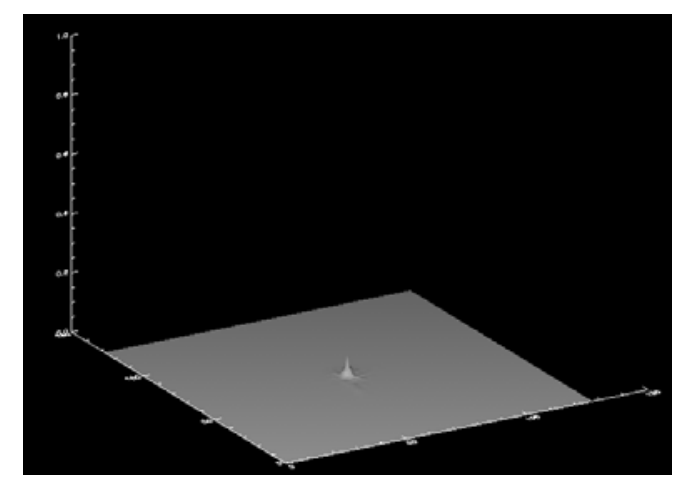

(c) PSF without AO correction.

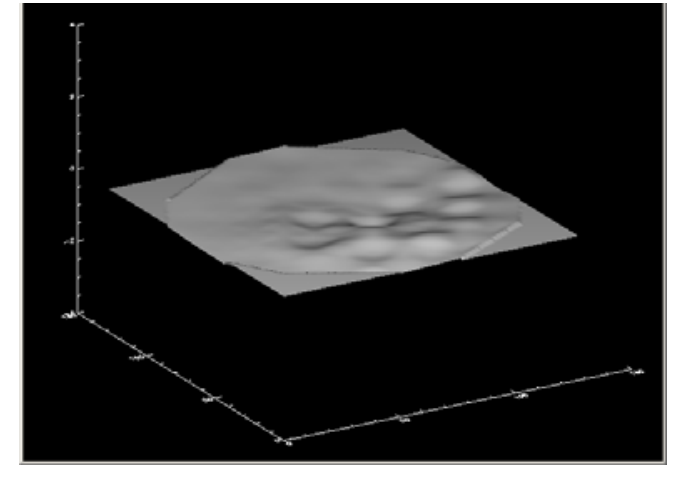

(b) WF Map with AO correction.

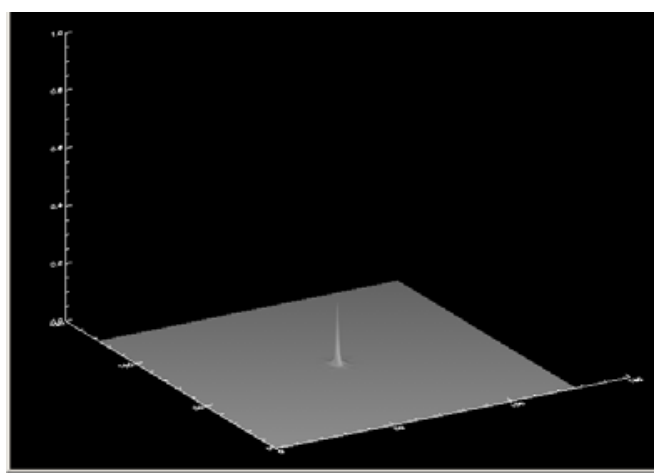

(d) PSF with AO correction.

Figure 2. 


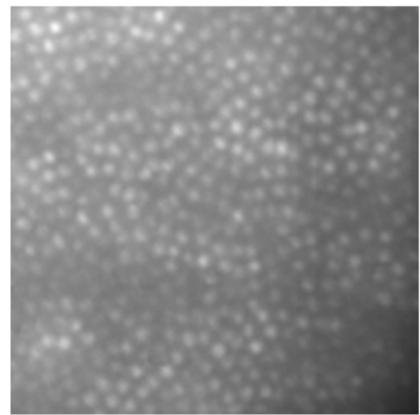

(a) Cropped original retinal image

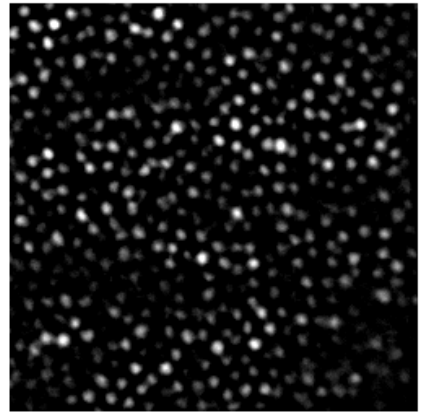

(b) Retinal image after background subtraction

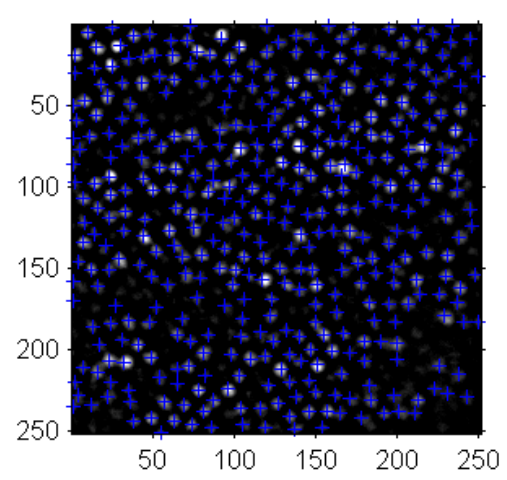

(c) Cone count result

Figure 3. 


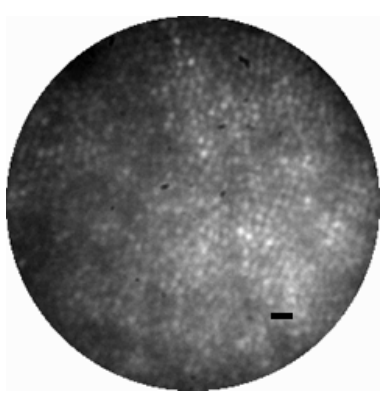

(a) $2^{\circ} \mathrm{NVF}$

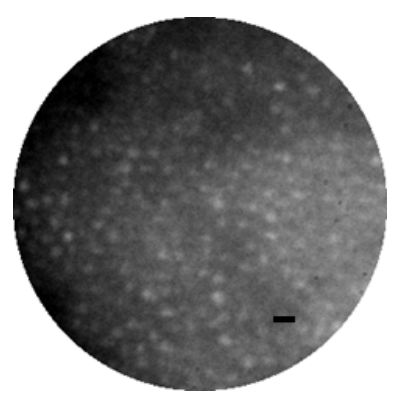

(d) $4^{\circ} \mathrm{N} 4^{\circ} \mathrm{IVF}$

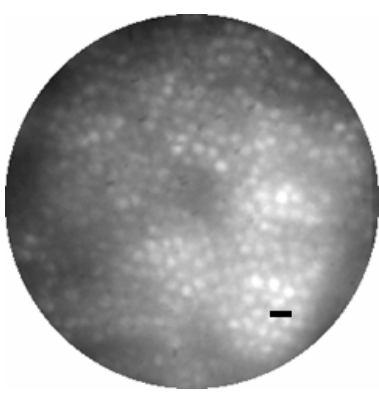

(b) $4^{\circ} \mathrm{NVF}$

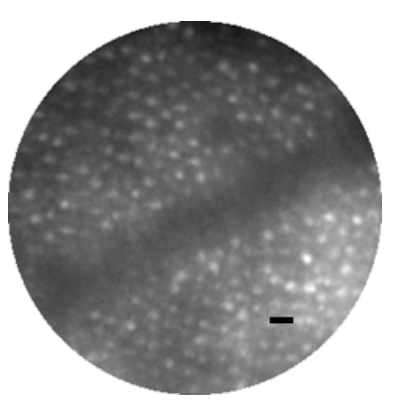

(e) $7^{\circ} \mathrm{N} 3^{\circ} \mathrm{SVF}$

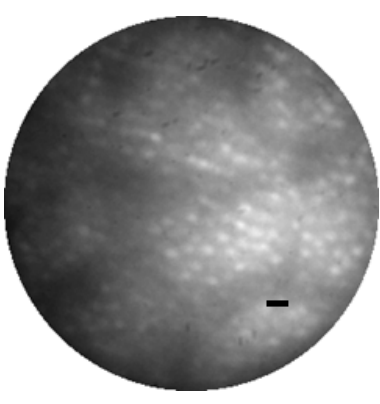

(c) $7^{\circ} \mathrm{NVF}$

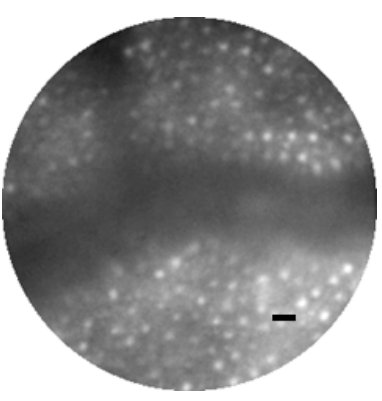

(f) $7^{\circ} \mathrm{N} 6^{\circ} \mathrm{SVF}$

Figure 4. 


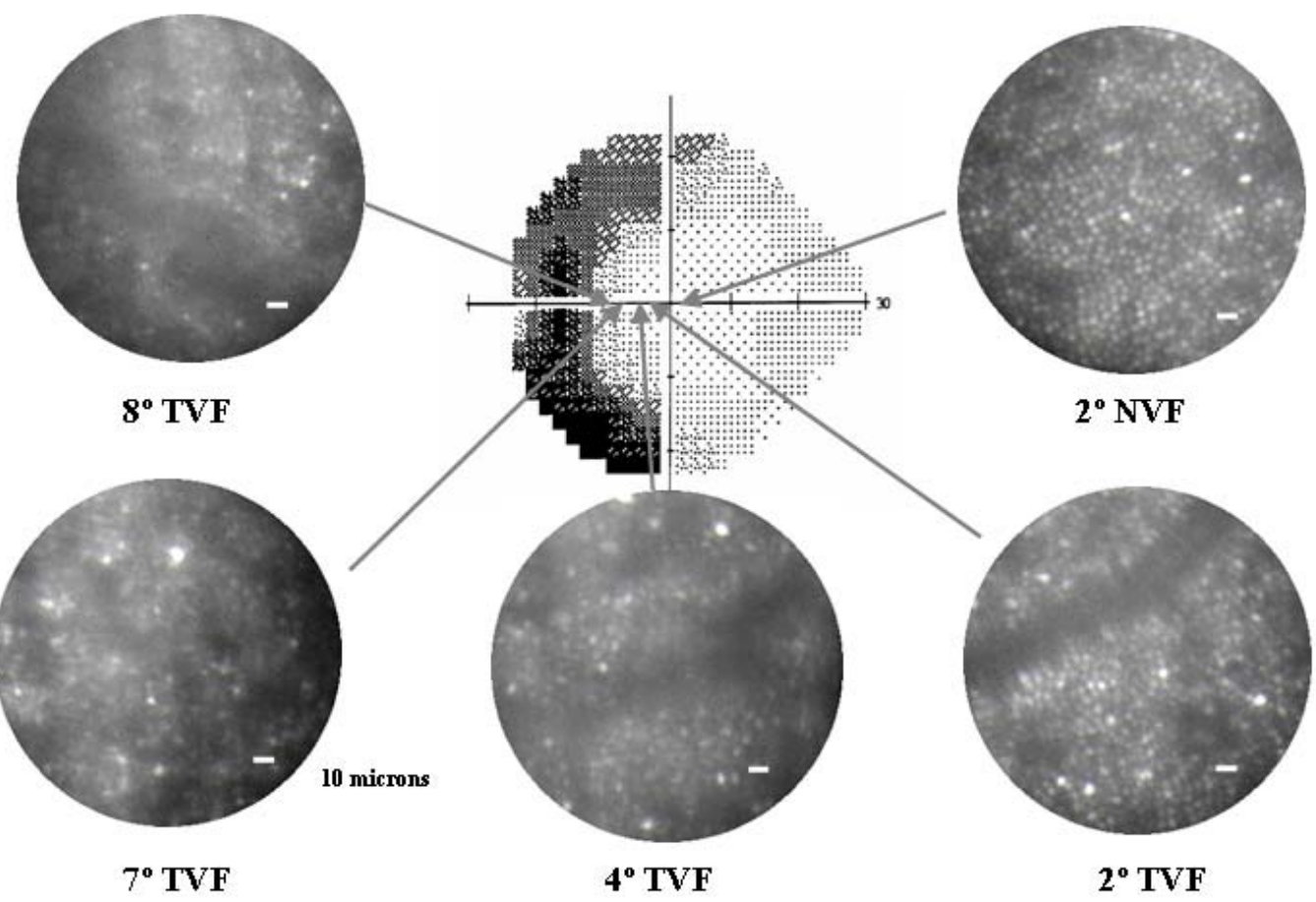

(a) Subject RCD 1; Rod-cone dystrophy (OS)

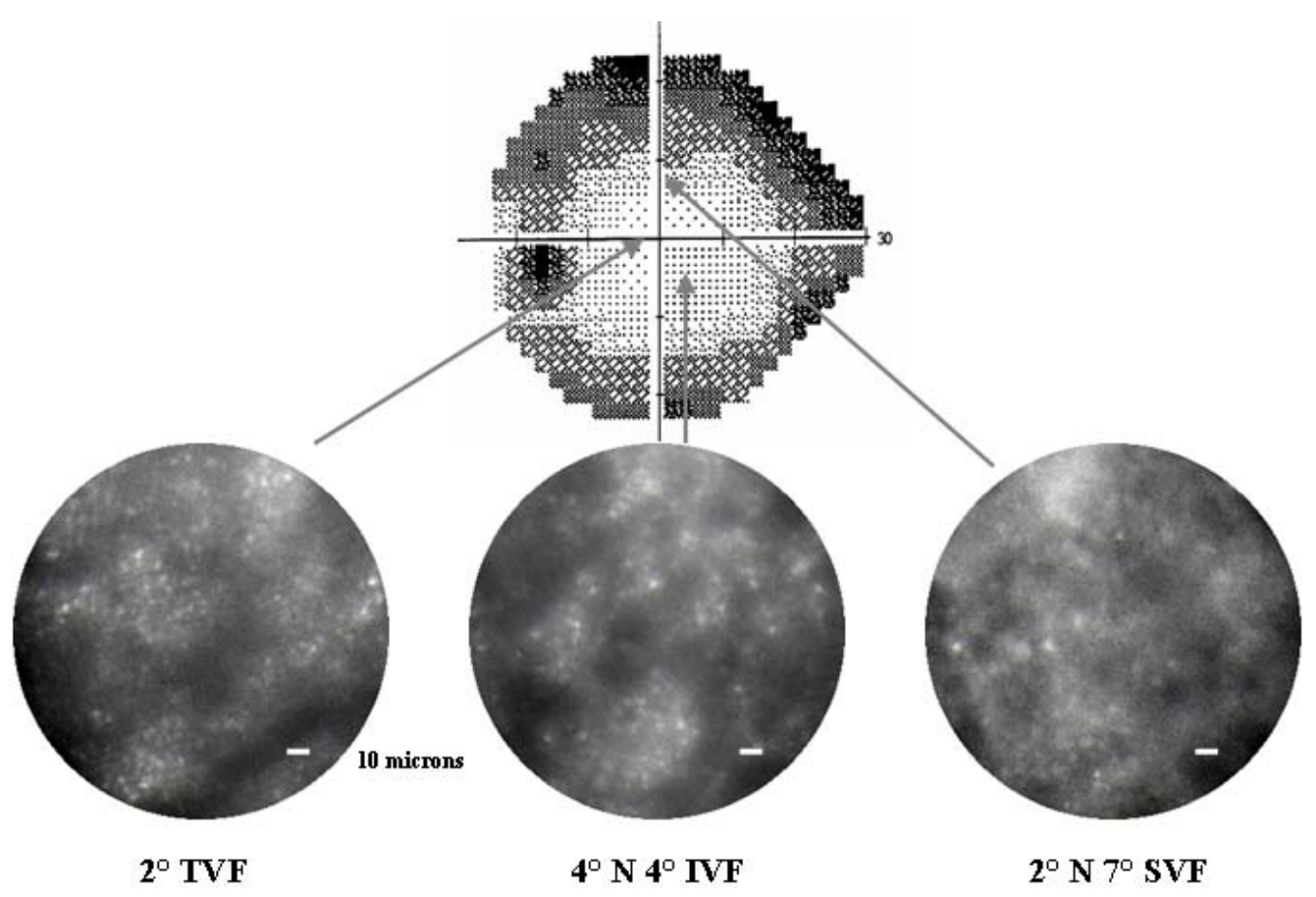

(b) Subject RCD 2; Rod-cone dystrophy (OS) 


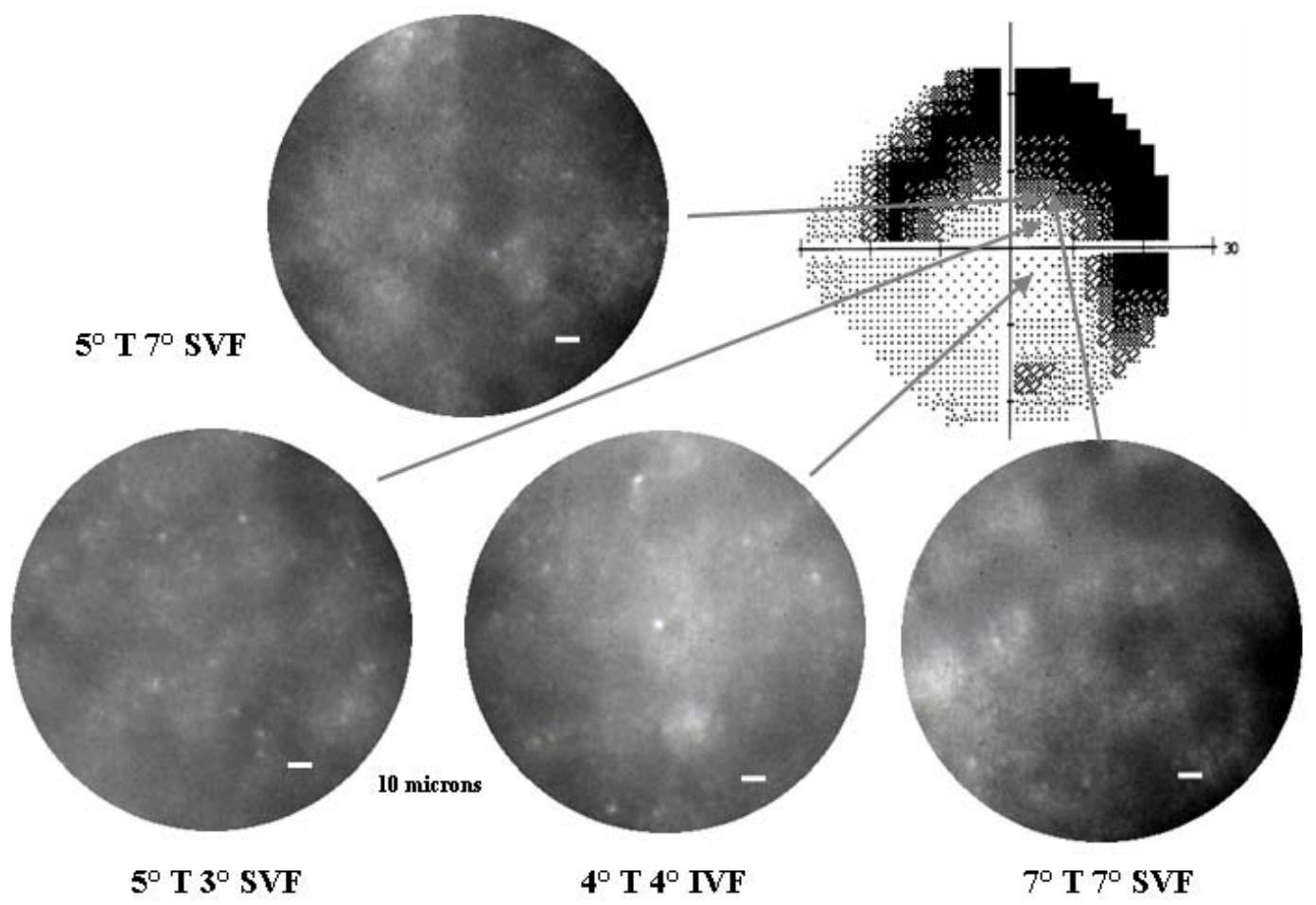

(c) Subject RCD 3; Rod-cone dystrophy (OD)

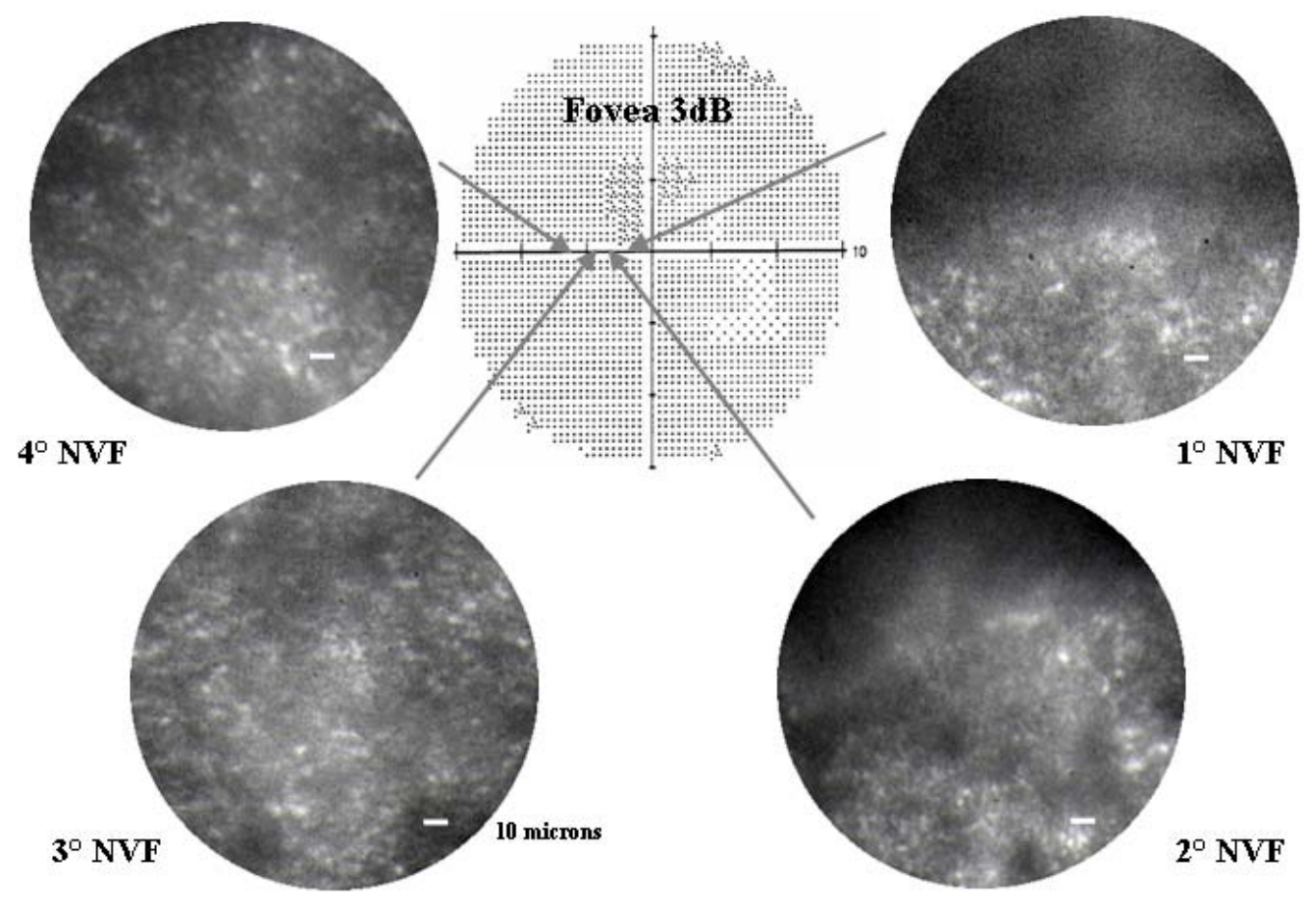

(d) Subject CRD; Cone-rod dystrophy (OD) 


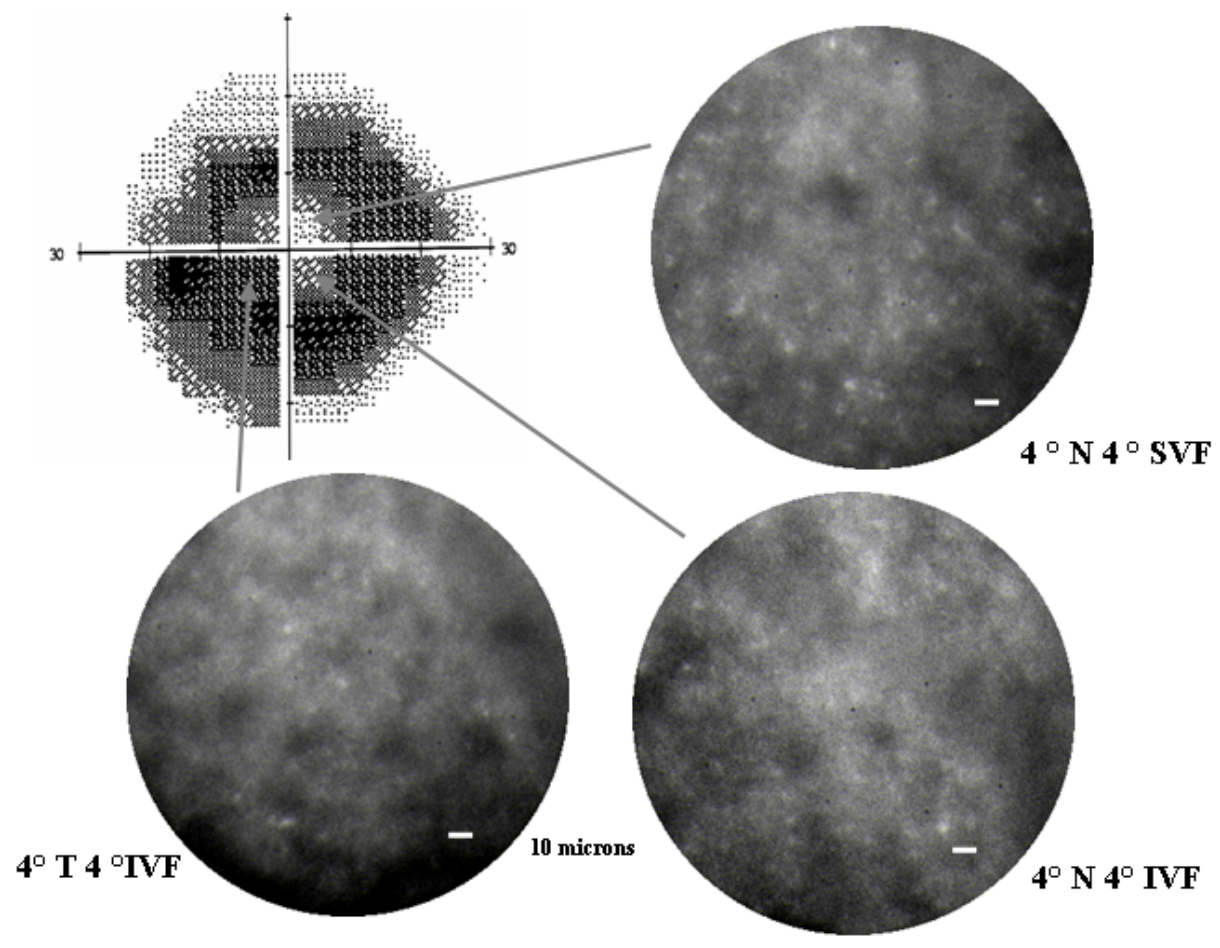

(e) Subject CD; Cone dystrophy (OS)

Figure 5. 


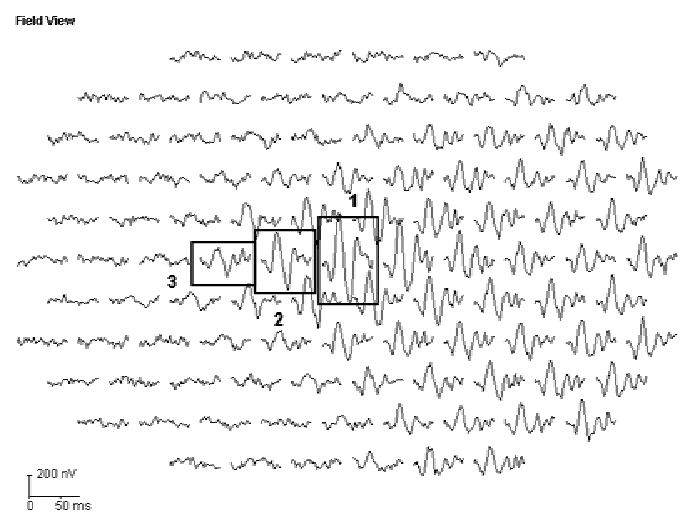

(i)

(a) Subject RCD 1; OS, Rod-cone dystrophy. The line plots (from top to bottom) correspond to (average response of $2^{\circ} \mathrm{NVF}$ and $2^{\circ} \mathrm{TVF}$ ), $4^{\circ} \mathrm{TVF}$ and (average response of $7^{\circ} \mathrm{TVF}$ and $8^{\circ} \mathrm{TVF}$ ) respectively.

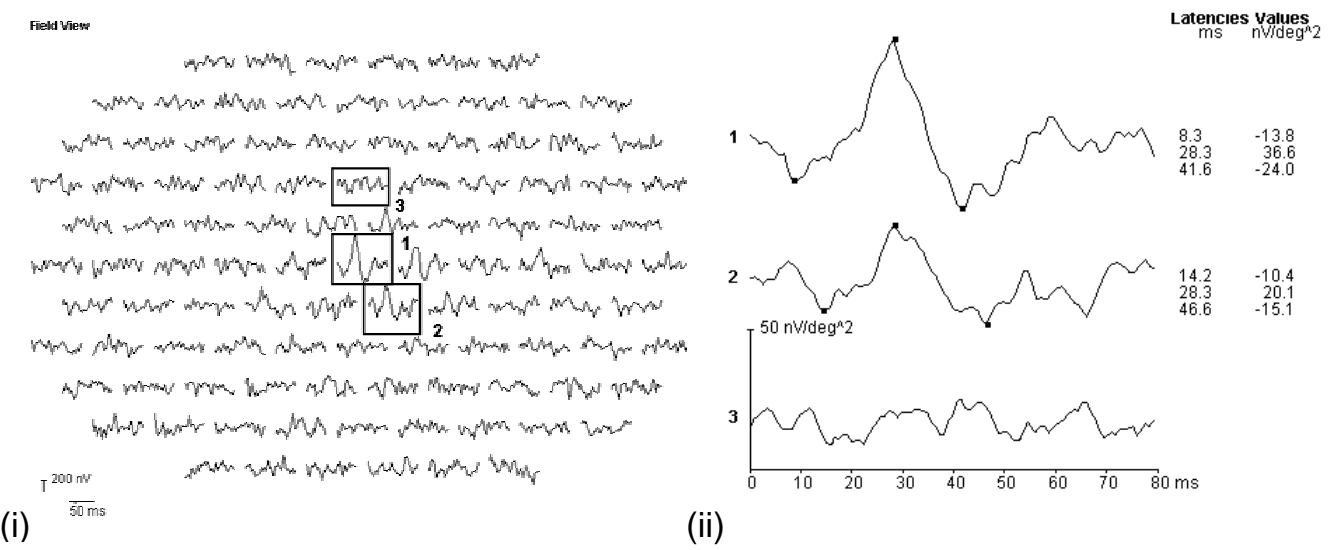

(b) Subject RCD 2; OS, Rod-cone dystrophy. The line plots (from top to bottom) correspond to $2^{\circ}$ TVF, $4^{\circ} \mathrm{N} 4^{\circ}$ IVF and $2^{\circ} \mathrm{N} 7^{\circ}$ SVF respectively.

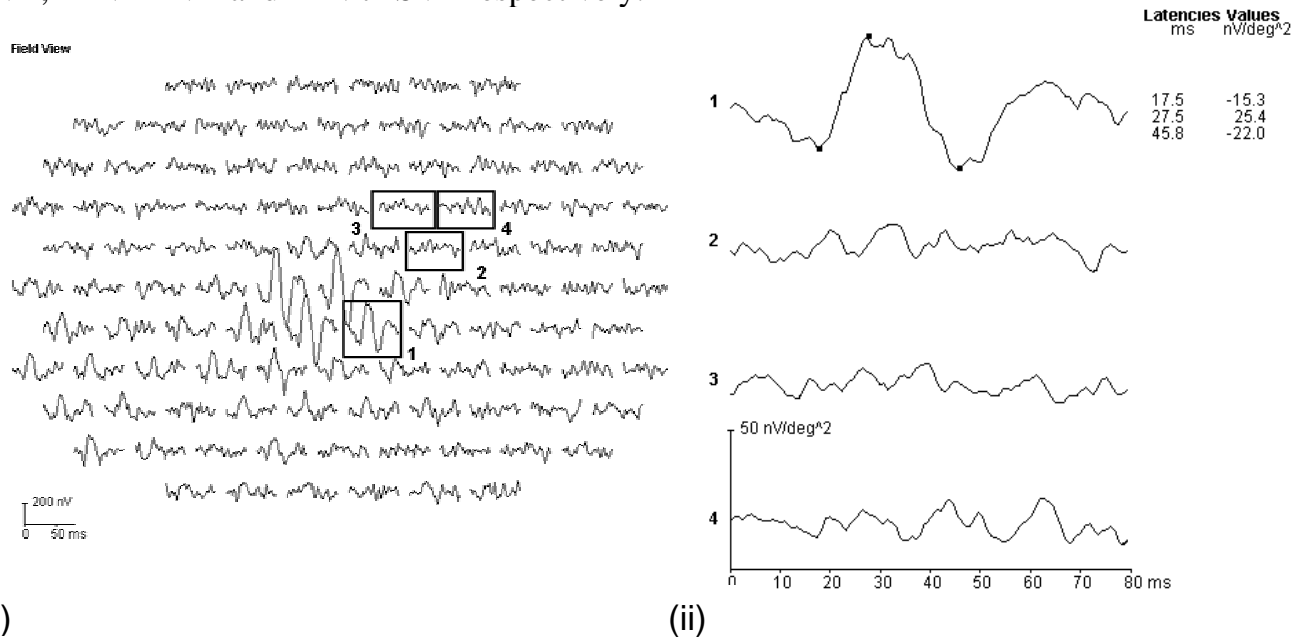

(c) Subject RCD 3; OD, Rod-cone dystrophy. The line plots (from top to bottom) correspond to $4^{\circ}$ $\mathrm{T} 4^{\circ} \mathrm{IVF}, 5^{\circ} \mathrm{T} 3^{\circ} \mathrm{SVF}, 5^{\circ} \mathrm{T} 7^{\circ} \mathrm{SVF}$ and $7^{\circ} \mathrm{T} 7^{\circ} \mathrm{SVF}$ respectively. 

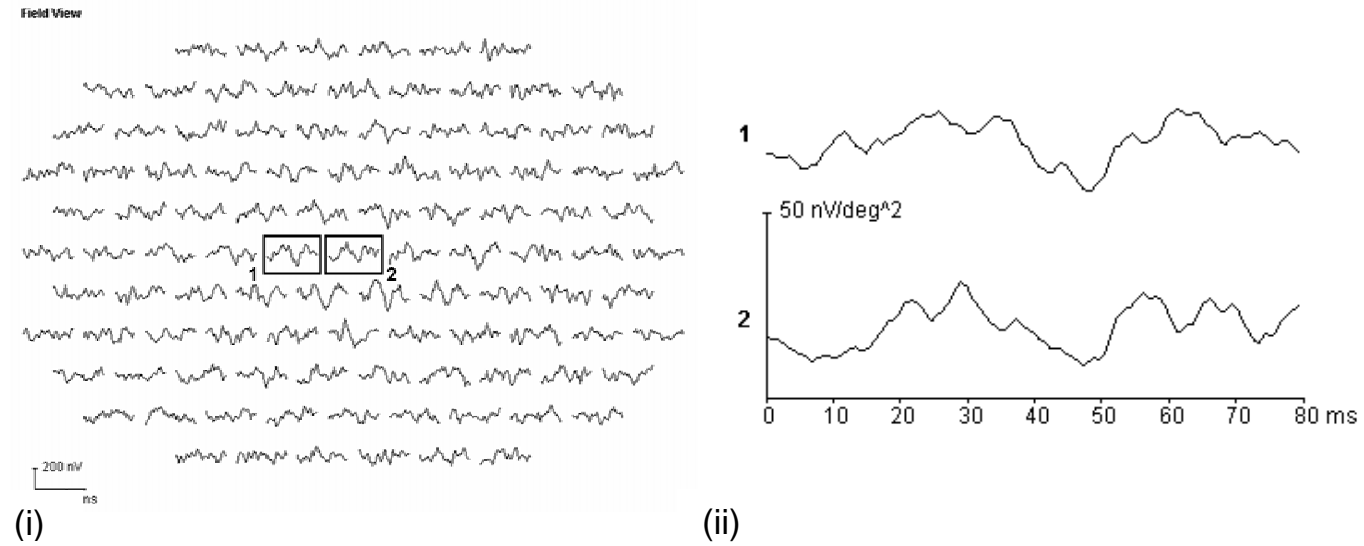

(ii)

(d) Subject CRD; OD, Cone-rod dystrophy. The line plots (from top to bottom) correspond to (average response of $3^{\circ} \& 4^{\circ} \mathrm{NVF}$ ) and (average response of $1^{\circ} \& 2^{\circ} \mathrm{NVF}$ ) respectively.

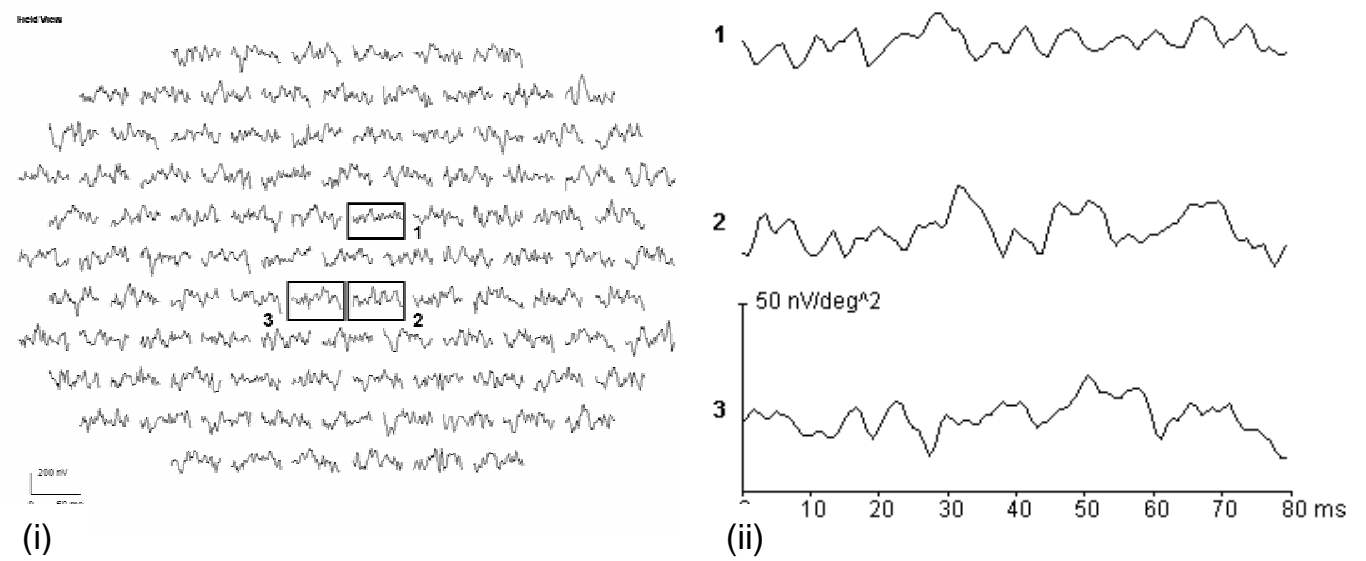

(e) Subject CD; OS, Cone dystrophy. The line plots (from top to bottom) correspond to $4^{\circ} \mathrm{N} 4^{\circ}$ $\mathrm{SVF}, 4^{\circ} \mathrm{N} 4^{\circ}$ IVF and $4^{\circ} \mathrm{T} 4^{\circ}$ IVF respectively.

Figure 6. 

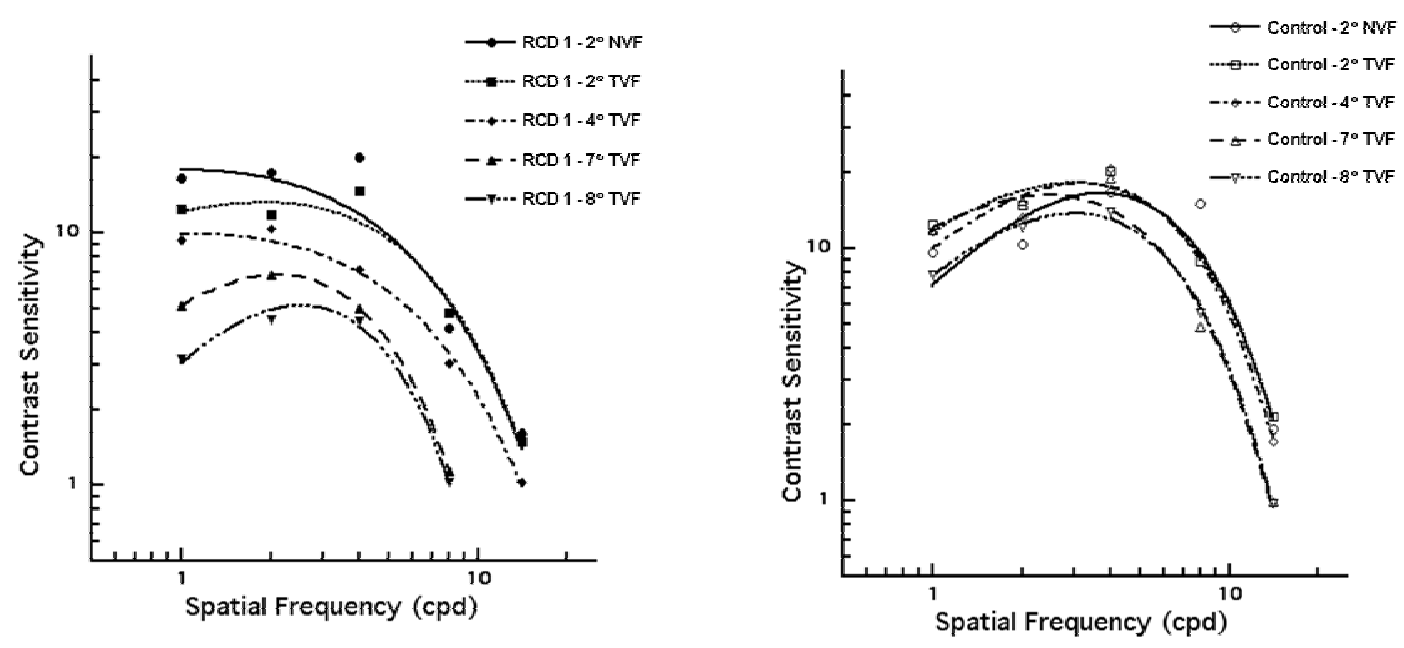

(a) Subject RCD 1; Rod-cone dystrophy (OS)
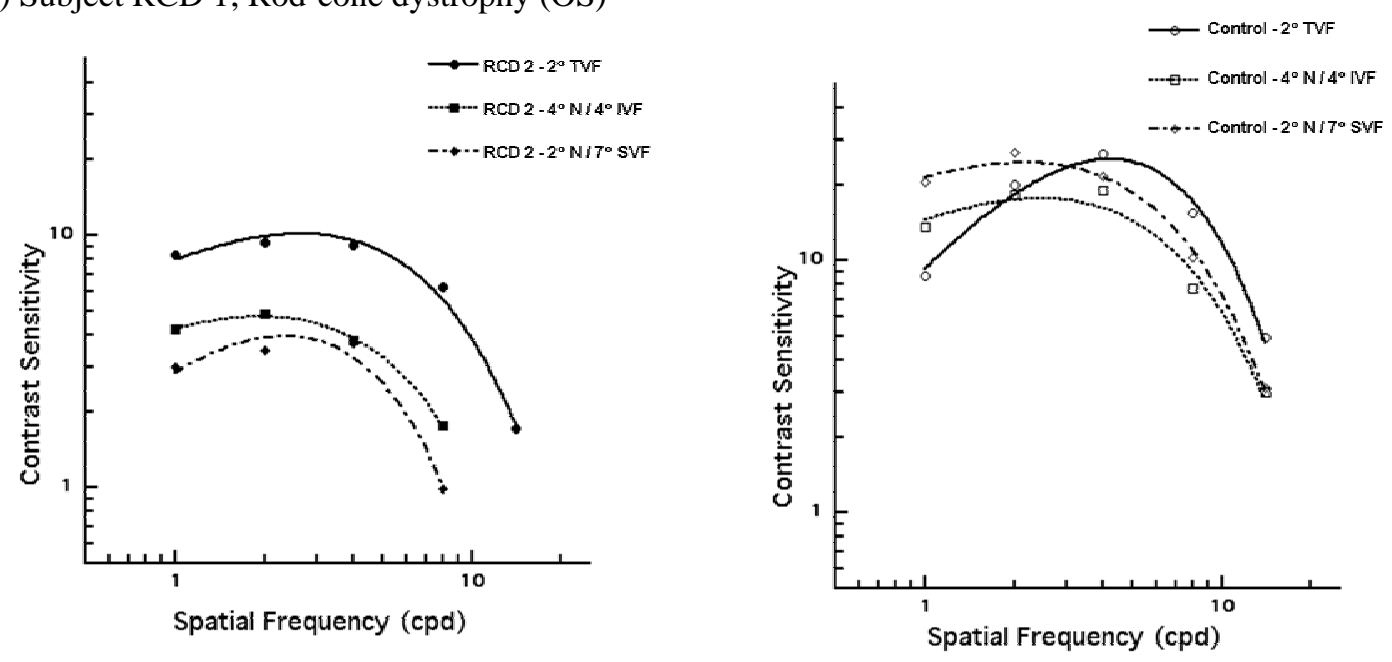

(b) Subject RCD 2; Rod-cone dystrophy (OS)
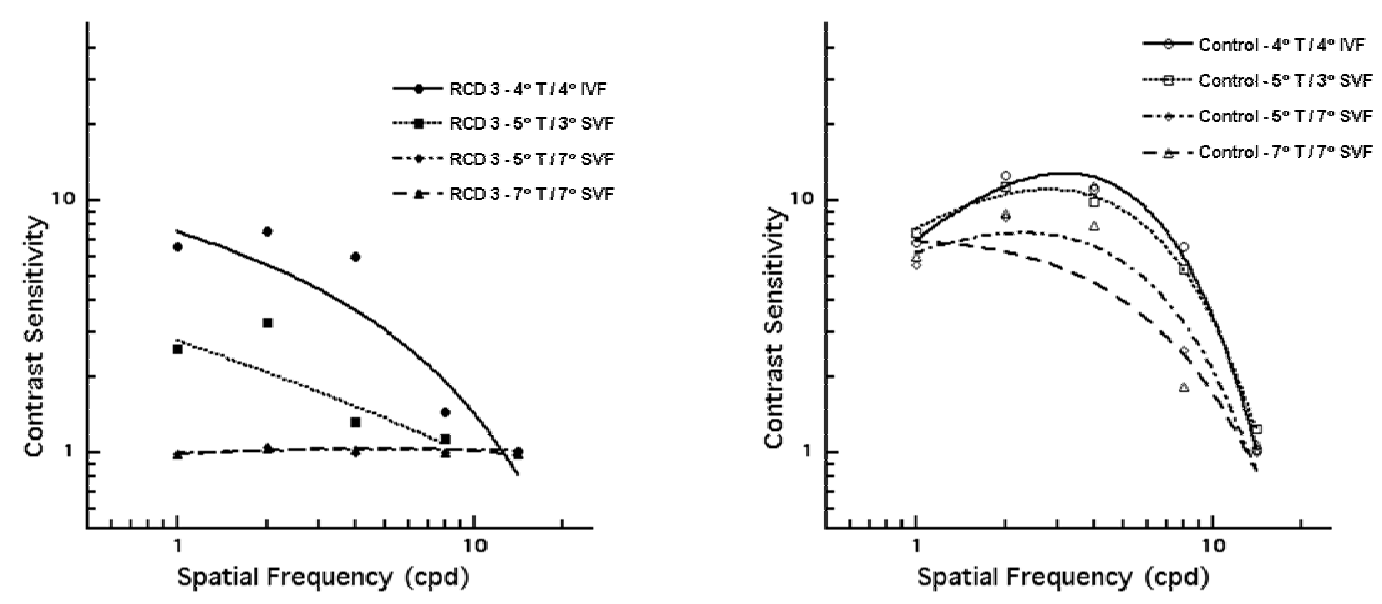

(c) Subject RCD 3; Rod-cone dystrophy (OD) 

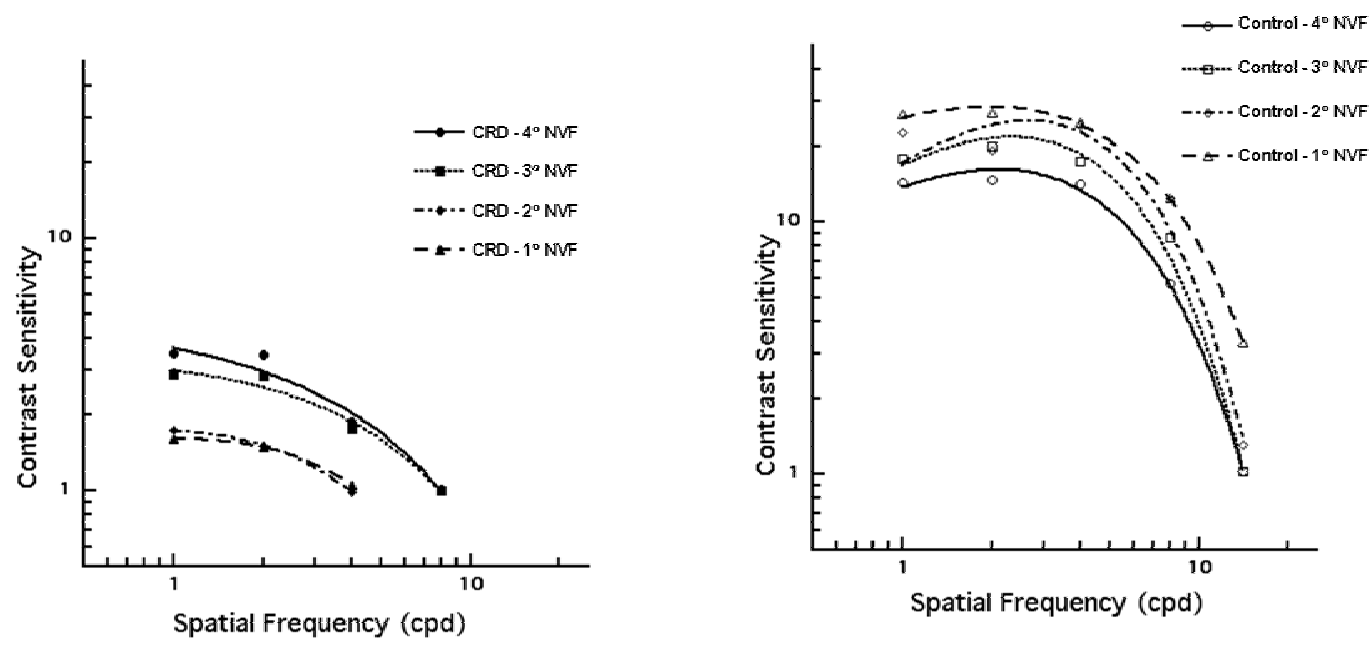

(d) Subject CRD; Cone-rod dystrophy (OD)
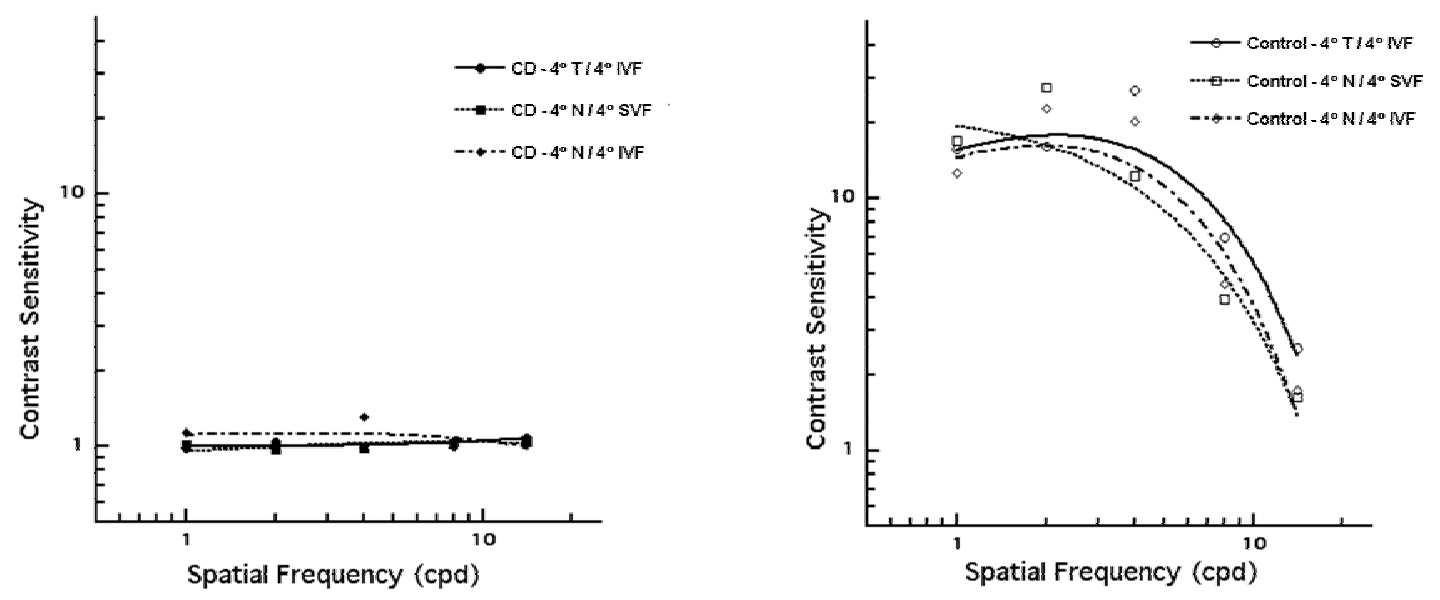

(e) Subject CD; Cone dystrophy (OS)

Figure 7. 